\title{
Pleuropulmonary changes induced by ergoline drugs
}

\author{
P. Pfitzenmeyer*, P. Foucher**, G. Dennewald+, B. Chevalon++, \\ D. Debieuvre\#, P. Bensa*\#, F. Piard†, P. Camus**
}

Pleuropulmonary changes induced by ergoline drugs. P. Pfitzenmeyer, P. Foucher, G. Dennewald, B. Chevalon, D. Debieuvre, P. Bensa, F. Piard, P. Camus. CERS Journals Ltd 1996.

ABSTRACT: Classic ergolines, such as bromocriptine, methysergide and ergotamine, can induce chronic pleuropneumonitis. We present the cases of eight patients who developed similar changes whilst on other ergolines.

In this retrospective case study spanning 1985-1995, clinical data, radiological material, pulmonary function, bronchoalveolar lavage and histopathology were reviewed. Earlier literature on ergoline-induced pleuropulmonary changes was reviewed.

Eight middle-aged to elderly individuals of both sexes developed pleuropulmonary changes during long-term therapy with regular dosages of nicergoline $(n=4)$, dihydroergocristine $(n=3)$, or dihydroergotamine $(n=1)$. Bibasilar pleural thickening with or without pleural effusion was present on chest radiographs and computed tomographic (CT) scans in six cases. Increased erythrocyte sedimentation rate was seen in most. Pure interstitial pneumonitis developed in two patients on dihydroergocristine and was reversible in each. Bronchoalveolar lavage was performed in four cases and was abnormal in all, but demonstrated no consistent pattern. Most patients exhibited lung restriction. The outcome was favourable showing slow improvement in all cases following discontinuation of the ergoline. Slight residual pleural thickening was seen in five out of the six cases with pleural involvement.

Nicergoline and dihydroergotamine can induce a syndrome of chronic pleural thickening/effusion that slowly improves after drug withdrawal. Dihydroergocristine can induce reversible interstitial pneumonitis.

Eur Respir J., 1996, 9, 1013-1019.
Services de *Gériatrie, **Pneumologie et Réanimation Respiratoire, \#Dermatologie et ${ }^{\dagger}$ Anatomie-Pathologique, Centre Hospitalier Universitaire, Faculté de Médecine et Université de Bourgogne, Dijon, France. +Department de Pneumologie, Centre Cardiologique du Nord, Saint Denis, France. ${ }^{++}$Service de Médecine Pneumologique, Centre Hospitalier, Lens, France. "Service de Pneumologie et Allergologie, Centre Hospitalier Paul Morel, Vesoul, France.

Correspondence: Ph. Camus

Service de Pneumologie

$\mathrm{CHU}$

BP 1543

F-21034 Dijon

France

Keywords:

Drug-induced adverse effects in lung drug-induced adverse pleural reaction ergoline

ergot

pleural thickening

pleurisy

Received: July 111995

Accepted after revision December 81995
Several drugs used by neurologists (e.g. carbamazepine, dantrolene, hydantoins, fluoxetine and tricyclic antidepressants) can induce adverse respiratory reactions, such as pneumonitis with or without blood eosinophilia, noncardiogenic pulmonary oedema or a severe systemic hypersensitivity syndrome $[1,2]$. A distinctive pattern of pleuropulmonary changes was first described by GRAHAM et al. [3] in 1966. This syndrome occurred during the use of the ergoline drug, methysergide. Since that time, other cases have been reported during the use of methysergide [4-16], as well as other ergolines, such as bromocriptine [17-32], dopamine agonists [33, 34], and ergotamine $[12,35-40]$.

In the present report, we describe pleuropulmonary changes and/or pneumonitis in eight patients receiving ergolines, most of which had not been implicated earlier as causative agents for such changes. Furthermore, two of these cases developed ergoline-induced pneumonitis, a pattern of adverse effects hitherto undescribed during the use of such compounds [1, 41].

\section{Patients and methods}

The eight patients came from four different French medical institutions during the period 1985-1995. Since bromocriptine-induced pleuropulmonary changes have been well described in the recent past [17-32], only patients with adverse respiratory effects from other ergolines were studied. A systematic search for other possible causes for pleural changes was performed in each case. In particular, a careful history of possible occupational exposure to asbestos or tuberculosis was recorded. In the two patients with interstitial pneumonitis (Nos. 4 and 7), a careful search for other possible causes, such as exposure to aeroantigens was made but they were excluded. In each of the eight cases, a detailed drug history was taken, with particular emphasis on drugs that may potentially damage the respiratory system $[1$, 41].

Chest radiographs were available for review in all cases; computed tomographic (CT) scans were available in five cases and pulmonary function tests in seven. Fibreoptic bronchoscopy and bronchoalveolar lavage (BAL) were performed in five and four cases, respectively. A closedchest pleural biopsy was performed in one case and videoassisted thoracoscopic biopsy in two.

All patients were regularly followed-up after drug withdrawal and the shortest follow-up period was 10 months. Earlier literature was reviewed via the Index Medicus, Medline, and Current Contents. All data are presented as mean \pm SEM. 


\section{Results}

\section{Demographics}

Demographic data of the eight patients (five males and three females) are presented in table 1. Age ranged 55-86

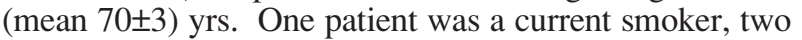
were ex-smokers and five were lifelong nonsmokers.

The ergoline in use was nicergoline (Sermion; Laboratoire Spécia, Groupe Rhone-Poulenc-Rorer, Paris, France) in four cases (Nos. 1, 2, 6 and 8), dihydroergocristine (Iskedyl: Laboratoire Pierre Fabre, Castres, France) in three (Nos. 3, 4 and 7), and dihydroergotamine (Laboratoire Sandoz, Rueil, France) in one (No. 5). The reason for prescription was stroke in two cases (Nos. 1 and 7), migraine in one (No. 5) and the so-called organic brain psychosyndrome of the elderly in five (Nos. 2, 3, 4, 6 and 8). Daily dosage was that recommended by the manufacturer in all cases. Treatment duration ranged between 8 months and 15 yrs (mean $62 \pm 15$ months) (table 1).

One patient (No. 5) recalled a possible but limited exposure to asbestos whilst she was employed as an ironer, as ironing boards used to be installed with asbestos in the past. Right-sided pleural tuberculosis had been suspected 58 yrs earlier in case No. 3, but no drug treatment had been given. Dantrolene, amitriptyline and naproxen had been taken in cases Nos. 1, 2 and 5, respectively.

\section{Thoracic changes (table 1)}

Symptoms developed insidiously and progressively over weeks or months. The exact time at which symptoms were first noticed was difficult to track in retrospect. Seven out of the eight patients complained of dyspnoea, three of cough and three of malaise and weight loss. Two patients complained of chronic chest pain. In these two, a work-up for coronary artery disease proved negative. Two patients presented with recurrent or chronic fever, not exceeding $38.8^{\circ} \mathrm{C}$. Moderately reduced breath sounds were noted in the bases in most cases, and crackles were heard at auscultation in three.

Pleural changes. Predominant pleural changes were seen in six of the eight cases, mainly in the form of pleural thickening in both costophrenic sulci in all six cases (figs. 1a and 2a). Definite pleural effusion amenable to thoracentesis was present in only one case (fig. 1a) and the pleural fluid was an exudate containing $43 \mathrm{~g}$ of proteins, 4,800 cells $\cdot \mathrm{mL}^{-1}$ of which $85 \%$ were lymphocytes. At CT examination, the pleura was diffusely thickened. However, changes were most prominent in lung bases (figs. $1 \mathrm{~b}$ and $2 \mathrm{~b}$ ), bilateral in all six cases, and asymmetrical in three. No patient had sharply demarcated pleural plaques, such as those seen following exposure to asbestos. Linear pleural calcifications were seen at CT scan in only one case (No. 5). At video-assisted thoracoscopic examination, pleural changes were confined to the parietal pleura, which appeared uniformly whitish and thickened. There were numerous adhesions between the parietal and visceral leaflets, but the latter appeared uninvolved.

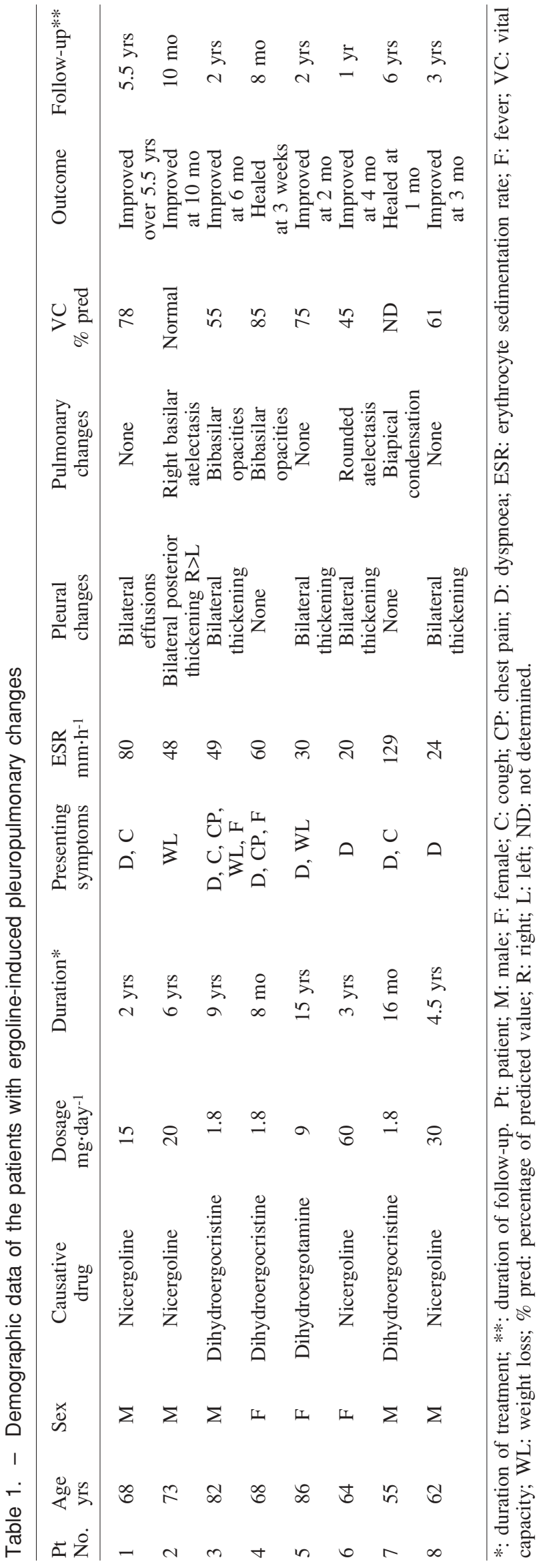


a)

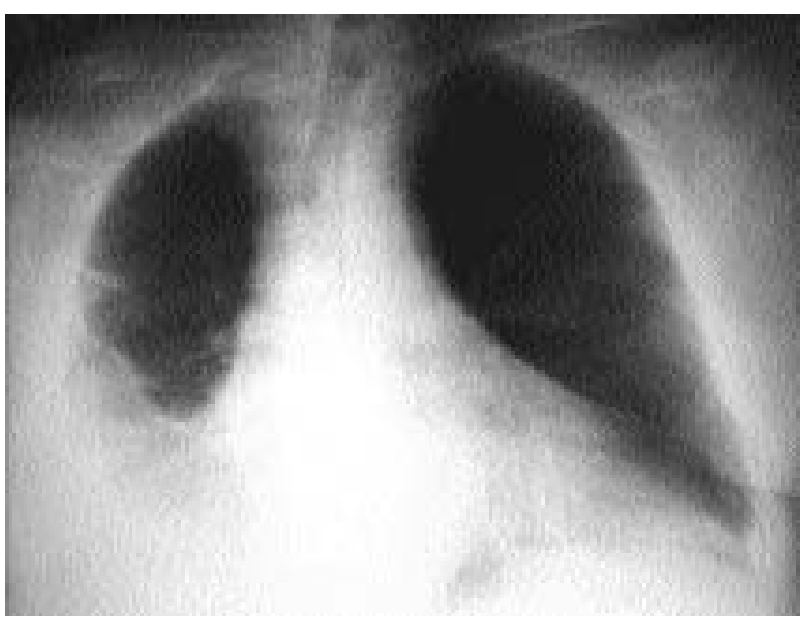

b)

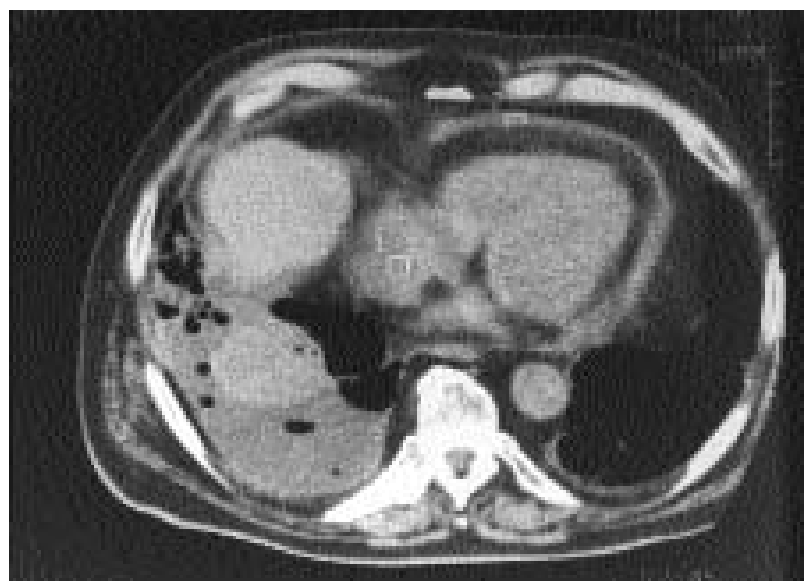

Fig. 1. - Case No. 1 a) (June 1989) bilateral pleural thickening, rightsided pleural effusion and enlarged cardiac silhouette after long-term treatment with nicergoline. b) Contemporary computed tomographic (CT) scan showing pleural and pericardial thickening/effusion.

Pulmonary changes. Two patients (Nos. 4 and 7) presented with interstitial lung disease, and dihydroergocristine was in use in both. In those with interstitial lung disease, duration of treatment with the ergoline tended to be shorter than in patients with pleural thickening (table 1). Dyspnoea was present and crackles were heard at the auscultation in both. Chest pain and fever were present in case No. 4. The chest radiograph showed a dense biapical infiltrate in case No. 7 (fig. 3 ) and bibasilar infiltrates in case No. 4 (not shown).

Bronchoalveolar lavage. An interpretable BAL was obtained in 4 of the 8 cases, the two with interstitial lung disease and two with pleural thickening. The total number of cells was within normal limits and averaged $247 \pm 29$ cells $\mu \mathrm{L}^{-1}$ of BAL fluid. The cellular BAL pattern was abnormal in all four cases, and included neutrophilia in cases Nos. 3 and 7 with figures of 25 and $50 \%$, respectively (normal: less than $3 \%$ ), and lymphocytosis in cases Nos. 4 and 5 with figures of 78 and $40 \%$, respectively (normal: less than 14\%). There was no correlation between BAL findings and the clinical-radiographic pattern of involvement. a)

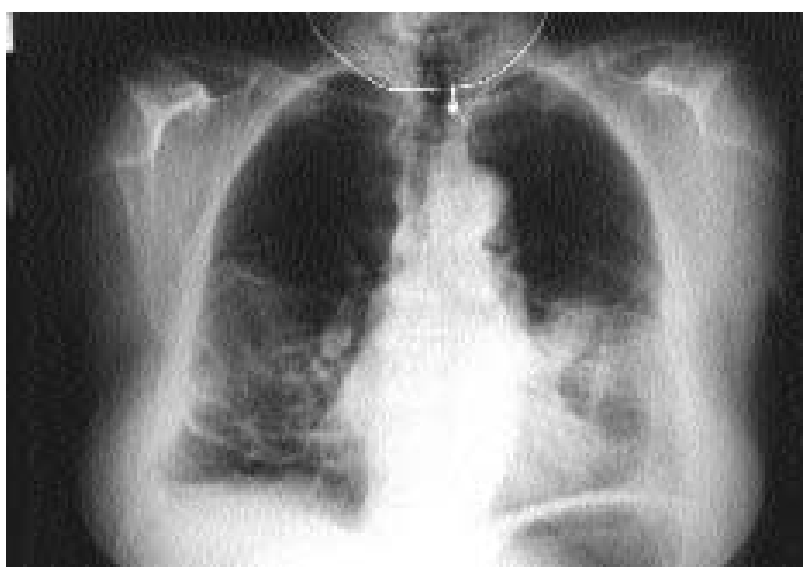

b)

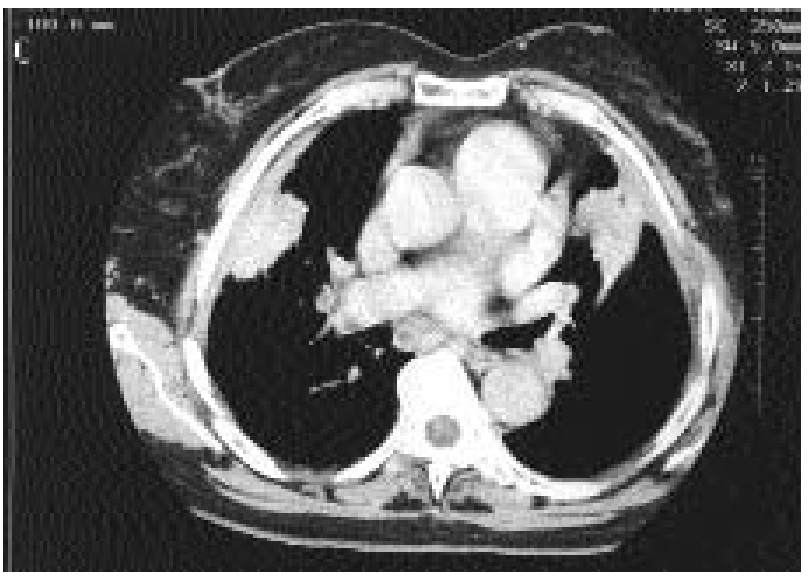

Fig. 2. - a) After 3 yrs of treatment with nicergoline (Case No. 6), pleural thickening, linear parenchymal opacities and lung masses developed. A pretherapy chest radiograph was normal. b) At computed tomography (CT), the masses faced areas of maximal pleural thickening and probably represented lung shrinkage or atelectasis.

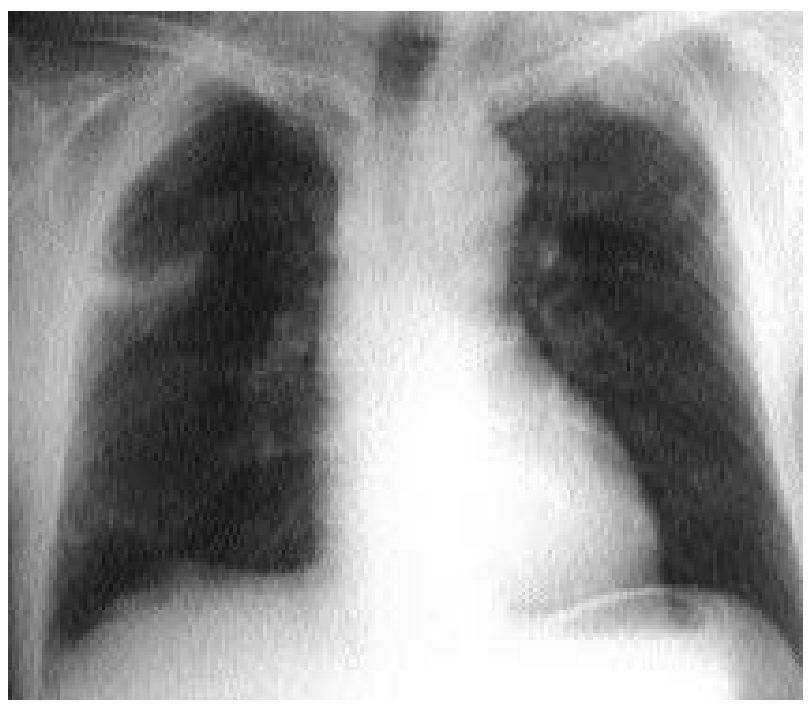

Fig. 3. - Biapical lung infiltrates during the use of dihydroergocristine (case No. 7). One month after withdrawal of the drug, lung infiltrates had cleared. 
Pulmonary function tests. A restrictive lung function defect (defined by a reduction both of forced expiratory volume in one second (FEV1) and vital capacity (VC) to less than $80 \%$ of predicted) was present in five out of the seven cases tested (table 1). FEV1 was slightly more reduced than $\mathrm{VC}$, with average values of $55 \pm 3$ and $63 \pm 4 \%$ of predicted, respectively.

Histopathology. Biopsy of the parietal pleura was performed in three cases (Nos. 1, 6 and 8). Histologically, the pleura was thickened by parallel layers of fibroblasts and intervening fibrosis. The inflammatory cellular infiltrate was sparse (fig. 4). Histology of the lung was available in none of our cases.

Pericardial changes. Pericardial thickening and effusion were detected on CT and echocardiography in case No. 1 , and the cardiac silhouette was enlarged on the chest radiograph (figs. 1a and b).

\section{Laboratory investigation}

Blood chemistry was normal in most cases. The blood neutrophil count was moderately raised in three patients. Erythrocyte sedimentation rate was increased in all eight cases (range 20-129 $\mathrm{mm} \cdot \mathrm{h}^{-1}$; mean $=55 \pm 11 \mathrm{~mm} \cdot \mathrm{h}^{-1}$ ). Antinuclear antibodies (ANA) were tested in five cases and stained weakly positive in three (Nos. 1, 4 and 5) and negative in two (Nos. 3 and 7). There was no correlation between ANA positivity and the clinical-radiographic pattern. Rheumatoid factor was tested in four cases and found positive in one at a level of 1 in 160 (No. 3).

\section{Follow-up}

The ergoline was simply withheld in seven of the eight cases. In addition, prednisolone was given in one case with interstitial pneumonitis (No. 4). All eight cases improved clinically and radiologically (compare figures $1 \mathrm{a}$ and $\mathrm{b}$ and $5 \mathrm{a}$ and $\mathrm{b}$ ). It took $\mathrm{a}$ few weeks for the chest radiograph to normalize in the two patients with interstitial pneumonitis. Improvement was slower in the six patients with pleural thickening, who improved gradually

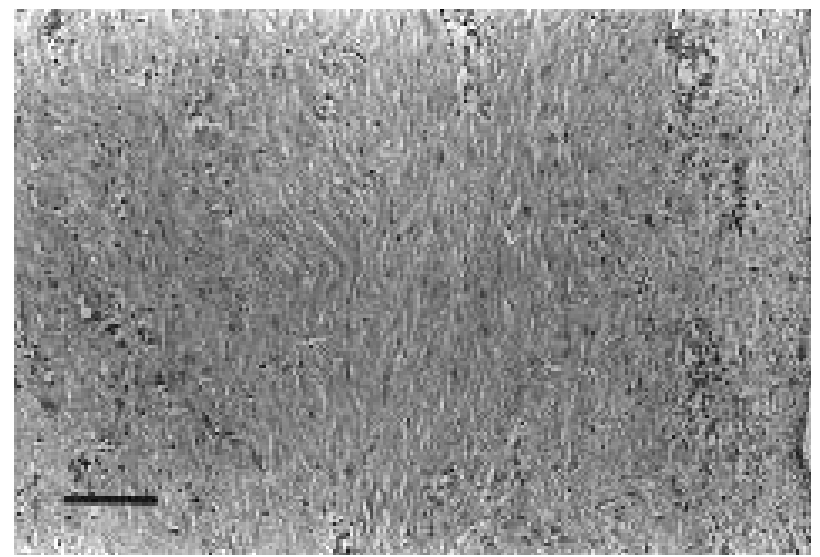

Fig. 4. - Biopsy of the parietal pleura obtained at thoracoscopy (case No. 6) showing marked pleural thickening by parallel layers of mature collagen and intervening fibroblasts. Inflammatory cells are sparse. (Haematoxyllin and eosin stain; magnification $\times 167$; bar=100 $\mu \mathrm{m}$ ). a)

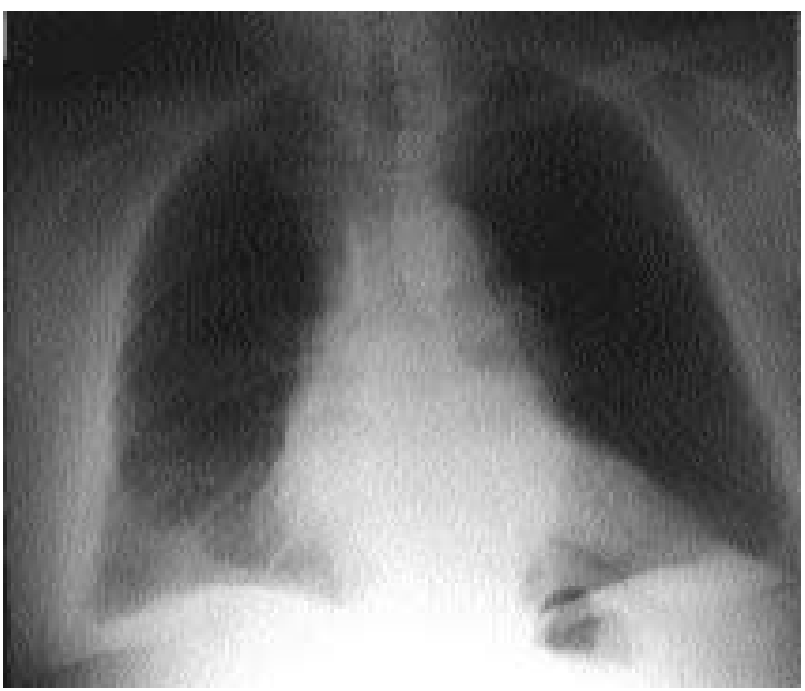

b)

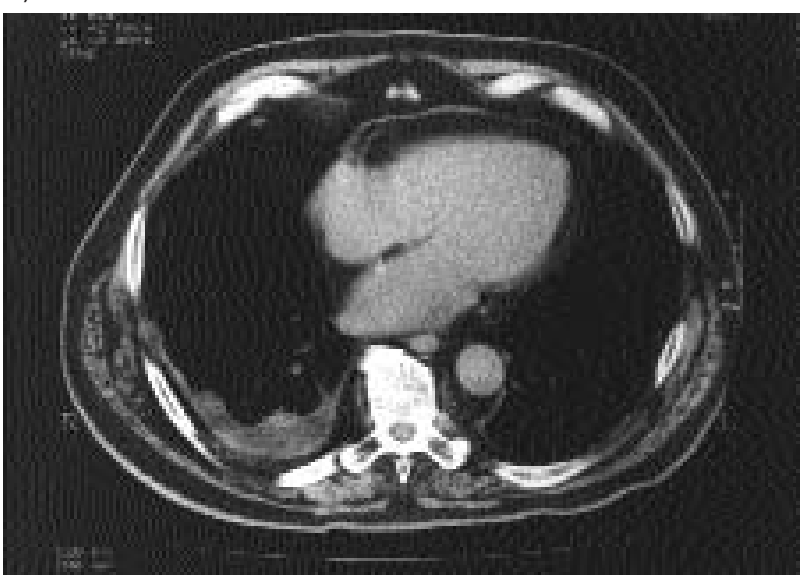

Fig. 5. - Case No. 1 (November 1994) five and a half years after discontinuation of nicergoline, pleural and pericardial effusion have progressively improved both on: a) the chest radiograph and b) the CT (computed tomography) scan.

over 2 months to 4 yrs. In four of the latter six cases, slight residual pleural thickening persisted in areas of previous pleural involvement.

Clinical-radiographic improvement translated into improvement in lung function in all cases tested. Mean VC increased from $63 \pm 4 \%$ of predicted at diagnosis to $84 \pm 3 \%$ of predicted 3 weeks to 6 months later. At the time of writing, seven patients are alive, asymptomatic and well, with little or no significant residual disease or impairment in lung function. Case No. 3 developed progressive dementia and died at 90 yrs of age. Eight hours following inadvertent rechallenge with dihydroergocristine in case No. 4, high-grade fever, dyspnoea, and substernal chest pain developed, but a chest radiograph was not taken. Rechallenge was not performed in the other cases.

\section{Discussion}

The eight patients developed either a syndrome of pleural thickening/effusion or, less often, reversible interstitial 
pneumonitis during long-term use of the ergolines, nicergoline, dihydroergocristine or dihydroergotamine.

A relatively long time interval elapsed in our patients between onset of clinical symptoms and recognition of the drug-induced nature of illness. This translated into an extensive work-up for such abnormalities before the proper diagnosis was suggested. We interpret this as evidence that many physicians are unfamiliar with ergoline-induced pleuropulmonary changes. Notably, the pleuropulmonary pattern of adverse reaction induced by ergolines is quite distinctive, as opposed to the pattern of interstitial pneumonitis seen with most other drugs [1,41].

Ascribing the pleuropulmonary changes seen in our patients to the drug they were taking required careful exclusion of other possible causes and aetiologies. In no case was there clinical or biological evidence of a systemic illness which might involve the pleura, such as rheumatoid arthritis, ankylosing spondylitis, mixed-connective tissue disease, lupus erythematosus or inflammatory bowel disease. Similarly, metastatic pleural effusion was ruled out because patients improved simply following cessation of the ergoline, and there was no evidence of cancer during follow-up periods extending up to five and a half years. Also, there was no clinical evidence of disseminated carcinoid disease, a recently recognized aetiological context for pleural thickening [43]. In one case, a history of pleural tuberculosis and in one case exposure to asbestos was elicited. However, once established, pleural thickening as a result of tuberculosis or asbestosis has not been reported to improve, and this contrasts with the observations in all our cases including these two, following discontinuation of ergoline.

Possible exposure to other drugs was carefully examined. The role of dantrolene, taken by patient No. 1, was ruled out because pleural changes predated institution of the drug and there was no eosinophilia, as opposed to published cases of dantrolene-induced pleural effusion $[1,41,42]$. Case No. 2 received amitriptyline and case No. 5 was exposed to naproxen. Both drugs had been associated with pulmonary infiltrates and eosinophilia, a clinical-pathological pattern clearly different from that seen in our cases. There was no exposure to other drugs.

Temporal relationships between exposure to ergolines and withdrawal of these drugs, as well as development and resolution of pleural changes were also instrumental in establishing the central role of these drugs. Interestingly, in case No. 6, a pretherapy chest radiograph was entirely normal, the pleural changes having developed progressively over 3 yrs of treatment with nicergoline and improved definitely after the drug was withheld.
Similarly, in all other cases, discontinuation of the ergoline led to definite and lasting improvement of the pericardial and/or pleural changes (figs. 1 and 5).

According to previous literature, therapy with such ergots as methysergide, bromocriptine and ergotamine has been linked to the development of retroperitoneal fibrosis [3, 4, 27, 31, 38, 44], fibrosing mediastinitis [16] and pleuropulmonary fibrosis [3-40]. Regarding extrapulmonary involvement, we do not believe that any of our patients had significant retroperitoneal fibrosis, because a renal sonogram showed normal kidneys and ureters in three cases (Nos. 1, 3 and 5), and renal function was normal in all eight cases. There was also no evidence for mediastinal fibrosis at $\mathrm{CT}$ scan examination in our cases [16].

The number of cases of pleuropulmonary change reported during the use of methysergide for migraine, bromocriptine for Parkinson's disease, and other ergolines is shown in table 2. Interestingly, adverse effects from dihydroergocristine and nicergoline, as described in the present report, have not previously been reported. Duration of treatment ranged between 3 weeks and 30 yrs and our patients fell into this wide range. Patients developed cough, chest pain, friction rubs and bilateral pleural effusion and/or thickening, as did several of our cases. Unilateral pleural effusion has been described in several cases [4, 5, 8, 30, 38]. In all but one cases [30], pleural fluid was an exudate containing increased numbers of lymphocytes and/or eosinophils [5, 9, 28, 29, 32, 36], as seen in case No. 1. Pulmonary infiltrates in association with the pleural changes have been described in 16 of the 37 bromocriptine cases [17, 18, 22-26, 28, 29], in two ergotamine cases [36, 39], and in one cabergoline case [33]. Round or oval-shaped opacities corresponding to foci of parenchymal atelectasis facing areas of thickened presumably immotile or retracted pleura (the so-called "folded lung" or "rounded atelectasis" have consistently been reported $[4,9,12,32,34,36]$, and were also seen in two of our cases (fig. 2b). Lone pulmonary infiltrates, as seen in cases Nos. 4 and 7 (fig. 3)), have not previously been reported during the use of ergolines.

A restrictive lung function defect has been reported in several instances $[10,15,22,23,25,26,28,31,32,34$, $36,39,40]$, and we suspect increased pleural recoil to be the cause. Bronchoalveolar lavage was performed in three earlier cases and showed increased neutrophilia in two $[25,26]$ and lymphocytosis in one [34]. There are, thus, too few reports to derive valid conclusions on the possible role of BAL in the diagnosis of ergoline-induced pleuropneumonitis. Histologically, bland pleural fibrosis

Table 2. - Literature data on adverse respiratory disease during the use of ergolines

\begin{tabular}{lccccccc}
\hline Drug & $\begin{array}{c}\text { Pt } \\
\mathrm{n}\end{array}$ & Clinical usage & $\begin{array}{c}\text { Sex } \\
\mathrm{M} / \mathrm{F}^{*}\end{array}$ & $\begin{array}{c}\text { Age** } \\
\text { yrs }\end{array}$ & $\begin{array}{c}\text { Dosage } \\
\text { mg·day }{ }^{-1}\end{array}$ & Duration & Ref. \\
\hline Methysergide & 37 & Migraine & $15 / 9$ & $52 \pm 0.8$ & $1-8$ & 1 mo-6.5 yrs & {$[4-16]$} \\
Bromocriptine & 37 & PD & $37 / 0$ & $64 \pm 0.4$ & $22.5-90$ & 3 wk-4 yrs & {$[17-32]$} \\
Ergotamine & 12 & Migraine & $7 / 5$ & $49 \pm 2.1$ & $2-9$ & $2-30$ yrs & 3 \\
Dihydroergotamine & 1 & Migraine & $0 / 1$ & 57 & $3-9$ & 25 yrs & {$[12,35-40]$} \\
Cabergoline & 2 & PD & $2 / 0$ & $60 \pm 1.6$ & 10 & $2-14$ mo & {$[33,34]$} \\
Lisuride & 1 & PD & $0 / 1$ & 68 & 4 & 15 mo & {$[33]$} \\
\hline
\end{tabular}

*: number of males and females may be less than total number of published cases shown in column 2, because gender was not mentioned in all reports; **: mean \pm SEM. Pt: patients; M/F: males/females; PD: Parkinson's disease. 
with few inflammatory cells, as seen in our cases Nos. 1,6 and 8, was reported in several cases $[4,5,9,12$, $22,26,28,29,32,36,37]$, whilst associated lung fibrosis was documented in only a few instances $[4,22,26$, 28]. Pericardial thickening and moderate pericardial effusion, as noted our case No. 1, have occasionally been reported $[4,22,37,40]$, and only one patient with pericardial tamponade [11].

The vast majority of patients improved within a few months or years after ergoline was discontinued and no fatality was reported. Although steroids were used by some authors $[5,22,25,26]$, their benefit is difficult to ascertain. In any event, marked improvement does occur without the help of steroids, as documented in seven of our eight cases.

The pathophysiology of ergoline-induced pleural/pericardial thickening remains obscure. Ergolines have different pharmacological activities, for instance, methysergide is a serotonine antagonist whereas bromocriptine is a D1 dopamine antagonist [45]. Whilst these drugs share a common molecular ring system, they differ in their moieties attached to their core structure. Despite structural differences, ergolines as a whole behave as substances fibrogenic to mesothelia, mediastinum and retroperitoneum. Whether fibrogenicity of ergolines is related to their core structure, to a common metabolite or to their serotoninergic activity [33] is currently unclear. In this connection, excess endogenous production of serotinin, as seen in the carcinoid syndrome, may also be associated with pleural fibrosis [43]. Finally, pleural thickening as an adverse effect from drugs is almost specific to ergolines, and has been seen only with the use of practolol, a $\beta$ blocker recalled in 1976 [46]. The pathophysiology of ergoline-induced pneumonitis also remains an unsettled issue.

In summary, a unique syndrome of occasionally painful bilateral pleural thickening with or without pleural effusion, pericardial thickening with or without pericardial effusion, increased sedimentation rate or, less commonly, interstitial pneumonitis can develop in patients treated with several ergolines taken long-term. These changes resolve upon cessation of exposure to the drug. Serosal changes improve at a slower rate than lung changes.

\section{References}

1. Cooper JAD, White DA, Matthay RA. Drug-induced pulmonary disease. Part 2. Noncytotoxic drugs. Am Rev Respir Dis 1986; 133: 488-505.

2. De Vriese ASP, Philippe J, van Renterghem DM, et al. Carbamazepine hypersensitivity syndrome: report of 4 cases and review of the literature. Medicine (Baltimore) 1995; 74: 144-150.

3. Graham JR, Suby HI, LeCompte PR, Sadowsky NL. Fibrotic disorders associated with methysergide therapy for headache. N Engl J Med 1966; 274: 359-368.

4. Graham JR. Cardiac and pulmonary fibrosis during methysergide therapy for headache. Am J Med Sci 1967; 254: $1-12$

5. Bays RP. Pleuropulmonary fibrosis following therapy with methysergide maleate: two case reports. J LA State Med Soc 1968; 120: 426-427.

6. Lindeneg O, Kok-Jensen A. Pleuritis og pleural fibrose opstaet under behandling med metysergid. Nord Med 1968; 79: 681-684.

7. Hindle W, Posner E, Sweetnam MT, Tan RSH. Pleural effusion and fibrosis during treatment with methysergide. Br Med J 1970; 1: 605-606.

8. Kok-Jensen A, Lindeneg O. Pleurisy and fibrosis of the pleura during methysergide treatment of hemicrania. Scand J Respir Dis 1970; 51: 218-222.

9. Dunn JM, Sloan H. Pleural effusion and fibrosis secondary to sansert administration. Ann Thorac Surg 1973; 15: 295-298.

10. Akoun GM, Herson S, Huchon G, Marsac JH. Fibrose pleuro-pulmonaire au methysergide avec complexes immuns circulants. Nouv Presse Med 1975; 4: 2809.

11. Meeran MK, Ahmed AH, Parsons FM, Anderson CK. Constrictive pericarditis due to methysergide therapy. $S$ Afr Med J 1976; 50: 1595-1597.

12. Gefter WB, Epstein DM, Bonavita JA, Miller WT. Pleural thickening caused by sansert and ergotartrate in the treatment of migraine. Am J Roentgenol 1980; 135: 375-380.

13. Lambard J, Vincent J, Roge JM, Akoun G, Michel PL. Fibrose pleuro-pulmonaire au methysergide. Nouv Presse Med 1981; 10: 2440-2441.

14. Hansen G, Abildgaard U, Skarpass IJK. Alvorlige bivirkninger av methysergid. T Norske Laegeforen 1986; 106: 2160-2166.

15. Muller R, Weller P, Chemaissani A. Pleurafibrose als Nebenwirkung einer langjahrigen Methysergid-Therapie. Dtsch Med Wschr 1991; 116: 1433-1436.

16. Sherrick AD, Brown LR, Harms GF, Myers JL. The radiographic findings of fibrosing mediastinitis. Chest 1994; 106: 484-489.

17. Rinne UK. Pleuropulmonary changes during long-term bromocriptine treatment for Parkinson's disease. Lancet 1981; i: 44.

18. Le Witt PA, Calne DB. Recent advances in the treatment of Parkinson's disease: the role of bromocriptine. J Neurol Transm 1981; 51: 175-184.

19. Bottcher AJ, Gron U. Pleuropulmonale forandringer ved bromokriptinbehandling af parkinsonisme. Ugeskr Laeger 1981; 143: 2648-2649.

20. Besser GM, Wass JAH. Pleuropulmonary shadows on bromocriptine. Lancet 1981; i: 323.

21. Krupp P. Pleuropulmonary changes during long-term bromocriptine. Lancet 1981; i: 44.

22. Vergeret J, Barat M, Taytard A, et al. Fibrose pleuropulmonaire et bromocriptine. Sem Hôp Paris 1984; 60: 741-744.

23. Douvier JJ, Vergeret J, Taytard A, et al. La bromocriptine dans la maladie de Parkinson: toxicité pleuropulmonaire. Ann Med Interne 1985; 136: 416-418.

24. Tornling G, Unge G, Axelsonn G, Noring L, Granerus AK. Pleuropulmonary reactions in patients on bromocriptine treatment. Eur J Respir Dis 1986; 68: 35-38.

25. Mouysset B, Montastruc JL, Rostin M, et al. Bromocriptine et fibrose pleuro-pulmonaire. Therapie 1986; 41: $73-75$.

26. Wiggins J, Skinner C. Bromocriptine-induced pleuropulmonary fibrosis. Thorax 1986; 41: 328-330.

27. Ward CD. Pleuropulmonary and retroperitoneal fibrosis associated with bromocriptine treatment. Lancet 1987; i: $1706-1707$.

28. McElvaney NG, Wilcox PG, Churg A, Fleetham JA. Pleuropulmonary disease during bromocriptine treatment of Parkinson's disease. Arch Intern Med 1988; 148: 2231-2226. 
29. Kinnunen E, Viljanen A. Pleuropulmonary involvement during bromocriptine treatment. Chest 1988; 94: 1034-1036.

30. Diot E, Diot P, Le Rolland A, Joinville AP, et al. Epanchements pleuraux induits par la bromocriptine. Rev Mal Respir 1990; 7: 175-177.

31. Hely MA, Morris GJL, Lawrence S, Jeremy R, Genge S. Retroperitoneal fibrosis, skin and pleuropulmonary changes associated with bromocriptine therapy. Aust NZ J Med 1991; 21: 82-84.

32. Schmid PA, Suter T, Speich R, Eberli F, Greminger P. Bromocriptin-induzierte Pleuropneumopathie. Dtsch Med Wschr 1994; 119: 1543-1546.

33. Bhatt MH, Keenan SP, Fleetham JA, Calne DB. Pleuropulmonary disease associated with dopamine agonist therapy. Ann Neurol 1991; 30: 613-616.

34. Frans E, Dom R, Demedts M. Pulmonary changes during treatment of Parkinson's disease with a long-acting ergot derivative, cabergoline. Eur Respir J 1992; 5: 263-265.

35. Ibsen KK, Lindeneg O. Ergotaminbehandling og pleuritis. Ugeskr Laeg 1979; 141: 860.

36. Taal BG, Spierings ELH, Hilvering C. Pleuropulmonary fibrosis associated with chronic and excessive intake of ergotamine. Thorax 1983; 38: 396-398.

37. Robert M, Derbaudrenghien JP. Fibrotic processes associated with long-term ergotamine therapy. $N$ Engl J Med 1984; 311: 601 .
38. Malaquin F, Urban T, Ostinelli J, Ghedira H, Lacronique J. Pleural and retroperitoneal fibrosis from dihydroergotamine. N Engl J Med 1989; 321: 1760.

39. Zijlstra EE, Wilson JHP, Ouwendijk RJTh. Pleural fibrosis associated with ergotamine therapy. Eur J Intern Med 1990; 1: 245-247.

40. Allen MB, Tosh G, Walters G, Muers MF. Pleural and pericardial fibrosis after ergotamine therapy. Respir Med 1994; 88: 67-69.

41. Camus Ph, Gibson GJ. Adverse pulmonary effects of drugs and radiation. In: Brewis RAL, Corrin B, Geddes DM, Gibson G, eds. Respiratory Medicine. Philadelphia, WB Saunders, 1995; pp. 630-657.

42. Miller DH, Haas LF. Pneumonitis, pleural effusion and pericarditis following treatment with dantrolene. J Neurol Neurosurg Psychiatr 1984; 47: 553-554.

43. Moss SF, Lehner PJ, Gilbey SG, et al. Pleural involvement in the carcinoid syndrome. QJ Med 1993; 86: 49-53.

44. Jiménez-Jiménez FJ, Lopez-Alvarez J, Sanchez-Chapado $\mathrm{M}$, et al. Retroperitoneal fibrosis in a patient with Parkinson's disease treated with pergolide. Clin Neuropharmacol 1995; 18: 277-290.

45. Seaton A. Pleural and pericardial fibrosis after ergotamine therapy. Respir Med 1994; 88: 480.

46. Lombard JN, Bonnotte B, Maynadié M, et al. Celiprolol pneumonitis. Eur Respir J 1993; 9: 588-591. 